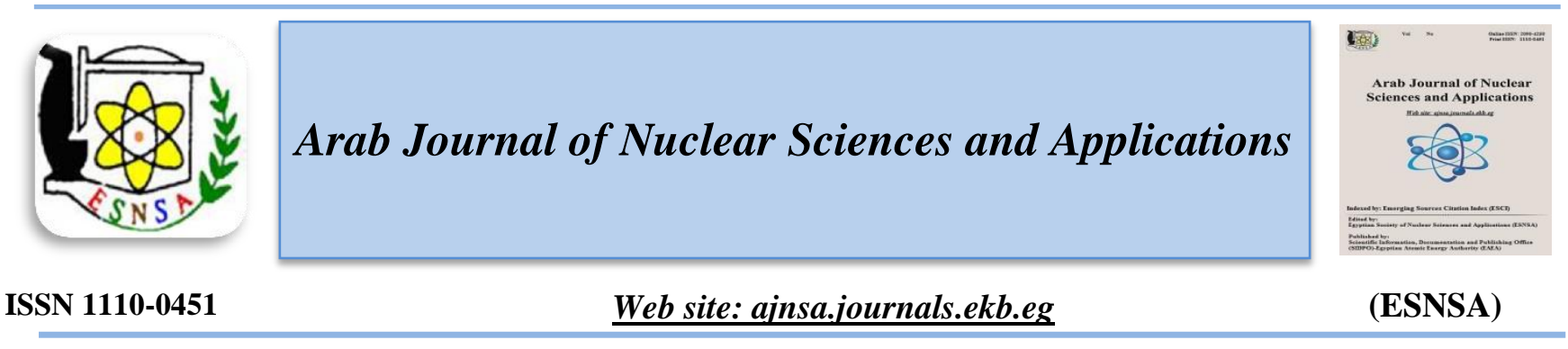

\title{
Synthesis and Characterization of Poly (vinyl alcohol) / Fullerene C60 Membrane via Chemical and Radiation Crosslinking
}

\author{
Aamer A. M. Alfayyadh ${ }^{\mathrm{a}}$, Mutasim I. Khalil ${ }^{\mathrm{b}}$, A. A. Basfar ${ }^{\mathrm{a}}$ and S. Lotfy*c \\ ${ }^{a}$ Radiation Technology Center, Nuclear Science Research Institute, King Abdulaziz City for Science and \\ Technology (KACST), Riyadh, Saudi Arabia \\ ${ }^{b}$ Department of Chemistry, Faculty of Science, King Saud University, Riyadh, Saudi Arabia \\ ${ }^{c}$ Polymer Chemistry Department, National Center for Radiation Research and Technology, Egyptian \\ Atomic Energy Authority, Cairo, Egypt
}

Received 17 June 2020 Fullerene C60 (FULL-C60) was used as a nano-filler in the preparation of the chemical-crosslinking Accepted 28 June 2020 polyvinyl alcohol (PVA) by glutaraldehyde (Glut) which is copolymerized with acrylate oligomers, 2carboxyethyl acrylate (CEA) followed by gamma irradiation. The effect of the FULL-C60 content on the gel content and swelling behavior of Glut-(PVA/CEA)-FULL-C60 copolymer hydrogel was investigated. The results revealed an increase in the gel content and a significant reduction in swelling of the nanocomposite material. There are influences for the PVA molecular weight, fullerene content, and absorbed dose on the gel content of the prepared nanocomposite. The irradiation of chemical crosslinked nanocomposites demonstrated approximately a $90 \%$ gelation over a range of $\mathbf{5 0 - 3 0 0} \mathbf{k G y}$ irradiation doses. A scanning electron microscopy (SEM) analysis showed a homogeneous distribution of nanocomposites in the composite matrix. The improvement in the thermal stability of radiation Glut(PVA/CEA) and Glut-(PVA-CEA)-FULL-C60 was evaluated using the thermogravimetric analysis Technique (TGA). The mechanical properties were examined via dynamic mechanical analysis (DMA) which showed significant variation because of the addition of nanocomposites and irradiation doses.

Keywords: Radiation; Poly (vinyl alcohol); Nanocomposite materials; Fullerene C60

\section{Introduction}

Carbon sphere-shaped molecules in the form of a hollow sphere called fullerene were discovered by Kroto et al.[1], which has turned to be a series now. It has nomenclature such as fullerene-60 or fullerene-70, in which all-carbon molecules with closed cage structures, have been found naturally in the Russian metaanthracite Shungite [2,3]. Fullerenes are composed of stacked graphene sheets similar in structure to graphite contain pentagonal or heptagonal rings similar in structure to graphite $[4,5]$. The interaction of fullerene with a polymer and the duration of fullerene-polymer intermolecular contacts may play an important role in the modification of properties of polymer systems through the addition of FULL-C60 [6]. Due to the large surface area of FULL-C60 its polymer nanocomposites investigation may get higher performance than usual reinforcement. FULL-C60 is considered perfect strengthening fillers in polymer nanocomposites with multifunction due to its excellent physical properties, nano size in diameter, and low-density. Grafting of the fullerene onto the biocompatible, water-soluble polymer such as PVA was thoroughly investigated in previous studies [7-11]. The polymeric materials' mechanical properties are strongly temperature-dependent[9].

Corresponding author: samaz711@yahoo.com

DOI: 10.21608/ajnsa.2020.33101.1368

CScientific Information, Documentation and Publishing Office (SIDPO)-EAEA 


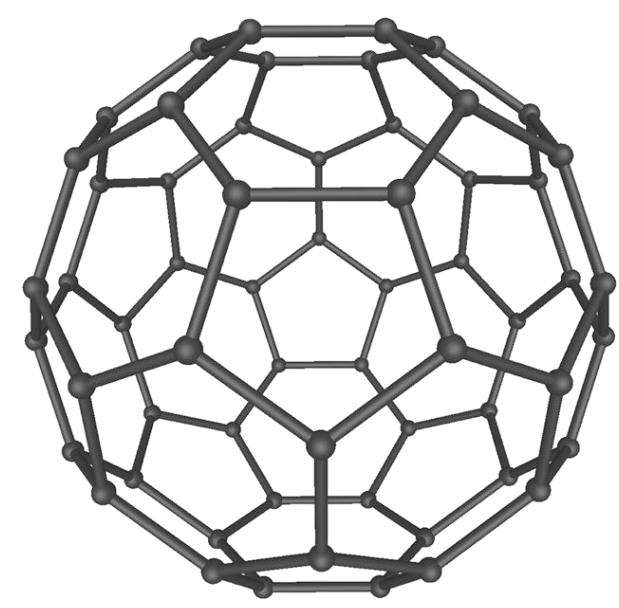

Photo (1): Spherical fullerene molecule with the formula FULL-C60

The stiff amorphous polymer at room temperature could behave in a rubbery manner at higher temperatures (rubbery modulus). The elastic portion of the material and the stored elastic energy modulus are the storage modulus (E'). The viscid portions of the material indicate energy dissipation which results in the loss modulus $\left(\mathrm{E}^{\prime \prime}\right)$ [14].

Ionizing radiation is a widely applicable technology in regulating the formation and properties of polymers, and could be used to adjust the achievement of bulk materials or surfaces[12]. Polymer hydrogels demonstrate a controlled gelation process[13]. The dose for which a minimum of the gel is formed can be defined as chemical modification of the gelation nanostructure [16,17]. Gamma irradiation treatment is considered a green technique and a safer non-contact modification, is as a prevalent technique for chemical modification of nanostructures in the fabrication of highperformance polymer composites[19]. Radiationinduced polymerization and crosslinking have advantages over chemical crosslinking and it is widely used in recent years for the synthesis of various hydrogels for biomedical applications[18]

A previous study of chemical and radiation crosslinked (PVA-CEA)-nanocomposites has been reported[18]. The crosslinked density between the polymer chain and nanotubes was improved by the radiation crosslinking of PVA and MWCNTs [19]. A significant reduction in the degree of swelling decreased dramatically up to $25 \mathrm{kGy}$ doses from 2250 to $1000 \%$ and the increases of the doses led to decreases in the swelling degree of the prepared nano-composites up to10 $\mathrm{wv}-1 \%$, finally, the degree of swelling for the prepared matrices did not increase more than $0.6 \%[20]$. An increase in the gel fraction that, $100 \%$ gelation achieved at 50 $\mathrm{kGy}$ of treated material, the authors found promising shape memory behavior [21]. The promising shape memory effect was found for the nano-composites[22].

In the present study of nanocomposites, comprised of PVA and CEA and FULL-C60, Glutaraldehyde is used as a crosslinking agent for (PVA/CEA) and (PVA/CEA)-FULL-C60. It was a challenge to develop high-performance chemical and radiation crosslinked (PVA/CEA) and (PVA/CEA)-FULLC60 nanocomposites as a hydrophobic polymeric matrix with strong interfacial interactions. In addition, the thermal and mechanical properties of nanocomposites were examined to understand the fundamental scientific drivers necessary to the characterization of the prepared nanocomposites.

\section{Materials and Methods \\ Materials}

2-Carboxyethyl acrylate oligomers (CEA) its molecular weight $170 \times 10^{3} \mathrm{~g} / \mathrm{mole}$ and PVA molecular weight of $16 \times 10^{3} \mathrm{~g} / \mathrm{mole}$ and $146 \times 10^{3} \mathrm{~g} / \mathrm{mole}, \quad 87-90 \%$ hydrolyzed were purchased from Sigma-Aldrich (St. Louis, USA). Fullerene C60, 99 \% (FULL-C60) were procured from Graven Chemical Industries Co. Ancora, Turkey. The anionic surfactant; sodium dodecyl sulfate (SDS) $>99 \%$ were purchased from Sigma-Aldrich (St. Louis, USA), and all chemicals were used as received.

\section{Synthesis of polymer networks via glutaraldehyde crosslinking}

The polymer was prepared using the previously reported procedure[23,24]. PVA solutions of 10 $\mathrm{w} / \mathrm{v}$ of different molecular weights, were prepared by dissolving PVA in water for 6 hours at $98{ }^{\circ} \mathrm{C}$. The ratio of 9:1 PVA: CEA solutions were mixed then cooled to room temperature. FULL-C60 at 0 to $0.5 \mathrm{~W} \mathrm{v} \mathrm{v}^{-1}$ percentage was dispersed in the previously prepared PVA-CEA solutions of MW $16 \times 10^{3} \mathrm{~g} / \mathrm{mole}$ and $146 \times 10^{3} \mathrm{~g} / \mathrm{mole}$ in the presence of the SDS surfactant as a stabilizing agent at a concentration of $0.5 \mathrm{w} \mathrm{v}^{-1}$ percentage. $\mathrm{HCl}$ was used to adjust the $\mathrm{pH}$ at 4 , then a certain amount of 25 percentage glutaraldehyde[25] was added to the PVA-CEA solutions under stirring conditions. The solution casting technic was used for PVA film preparation by casting the PVA-CEA solution onto a glass Petri dish then dried at $50{ }^{\circ} \mathrm{C}$. The films were left for 36 hours at room 
temperature $\left(25^{\circ} \mathrm{C}\right)$ to complete the chemical crosslinking and was carried out for 36 hours at room temperature $\left(25^{\circ} \mathrm{C}\right)$. The obtained films were washed with deionized water until the $\mathrm{pH}$ neutral conditions and dried using a vacuum oven.

\section{Radiation crosslinking}

The prepared chemical glutaraldehyde crosslinking films, according to the PVA molecular weight and the FULL-C60 concentrations of 0 to $0.5 \mathrm{w} \mathrm{v}^{-1}$ percentage were packed into polyethylene bags and irradiated to $0,50,150$, and $300 \mathrm{kGy}$ at room temperature using a 60Co gamma source (Gamma Cell 220; MDS Nordion, Canada).

\section{Swelling studies}

Pre-weighed specimens of glutaraldehyde crosslinked (PVA/CEA)-FULL-C60, according to PVA molecular weight and the FULL-C60 concentrations, were allowed to swell up to equilibrium at $37^{\circ} \mathrm{C}$ in $50 \mathrm{ml}$ distilled water. After drying the removed specimens from the water by filter papers to remove excess water then the specimens were weighed using a sensitive balance. The averaged values of three specimen's water uptake at equilibrium were reported. The swelling degree (\%) was determined from the equation. (1),

Swelling degree $(\%)=\frac{\text { Ws }- \text { Wo }}{\text { Wo }} * 100$

(1)

where Ws and Wo are the weights of the swollen and the dried hydrogel respectively.

\section{Gel fraction}

The gel content of the dried specimens of Glut(PVA/CEA)-FULL-C60 according to PVA molecular weight and the FULL-C60 concentrations were the average values of three specimens gel content were reported. estimated through the determining of its insoluble portion after boiling in distilled water for 48 hours at 60 ${ }^{\circ} \mathrm{C}$. The averaged values of three specimens of gel content were reported. The gel fraction was calculated according to equation (2).

$$
\operatorname{Gel}(\%)=\frac{\text { Mass of residue }(\mathrm{g})}{\text { Original mass }(\mathrm{g})} * 100
$$

The recorded values above $90 \%$ considered a good crosslinking yield.

$$
100-\operatorname{Gel}(\%)=\operatorname{sol}(\%)
$$

Thermogravimetric Analysis (TGA)

The thermogravimetric analysis (TGA) was executed a TGA apparatus (Perkin Elmer TGA7, USA) from room temperature up to $600{ }^{\circ} \mathrm{C}$ under a nitrogen atmosphere at a heating rate of 5 ${ }^{\circ} \mathrm{C} /$ minute.

\section{Dynamic Mechanical Analysis (DMA)}

DMA was carried out using PerkinElmer Inc. machine, USA. The specimens were equilibrated thermally at a very low temperatures $\left(-50^{\circ} \mathrm{C}\right)$ for three minutes and then heated up to $280{ }^{\circ} \mathrm{C}$ at a rate of $5{ }^{\circ} \mathrm{C} /$ minute. The initial conditions of the measurements were the static force equal $110 \mathrm{mN}$, the dynamic force equal $100 \mathrm{mN}$, and the frequency equal $1 \mathrm{~Hz}$. Tensile loading was used to determine the peak of the tan delta which defined to be the glass temperature $\left(\mathrm{T}_{\mathrm{g}}\right)$, the storage modulus ( $\left.E^{\prime}\right)$, the loss modulus ( $\left.E^{\prime \prime}\right)$, and the rubbery modulus (Er) of the specimens.

\section{Scanning Electron Microscopy (SEM)}

Scanning electron microscopy was utilized to study the cut edge of the specimens as a crosssectional and top view using JSM $5800 \mathrm{LV}$ from Joel Co., Japan. The maximum magnification of the SEM was 300,000 at a resolution of $3.5 \mathrm{~nm}$. Before the examination, the specimens were dried under sputters coated gold. All the micrographs were taken on a cut edge of the composites as a cross-sectional and top view.

\section{Results and Discussion}

Effect of irradiation dose on the gel fraction of the Glut-(PVA/CEA)-Nano-particles

Figure (1) shows these gel percentages of Glut(PVA/CEA)-FULL-C60 copolymer of the two molecular weights $16 \times 10^{3} \mathrm{~g} / \mathrm{mole}$ and $146 \times 10^{3} \mathrm{~g} / \mathrm{mole}$ of PVA as a function of irradiation dose and FULL-C60 content. As the FULL-C60, concentration increases, the crosslinking increases leading to more gel formation. The presence of CEA in the three compositions of the Glut-(PVA/CEA) with different fillers play an effective role in the gel formation. These results show the efficiency of radiation crosslinking of PVA and CEA copolymers through their $-\mathrm{OH}$ groups and vinyl groups. This is most likely due to the use of the vinyl groups decreases rapidly with increasing $\gamma$ radiation dose. [26]. 
Effect of irradiation dose on the swelling of the Glut-(PVA/CEA)-FULL-C60

Figure (2) shows the equilibrium swelling of Glut(PVA/CEA)-FULL-C60 copolymer of the PVA two molecular weights as a function of irradiation dose and FULL-C60 content. It is clear that the degree of swelling for Glut-(PVA/CEA)-FULLC60 copolymers did not exceed $0.5 \%$ for the PVA two molecular weights. The hydrogen bonding between hydroxyl groups of the PVA leads to high physical interactions between the polymer chains. The glutaraldehyde crosslinking decreases the number of hydroxyl groups and weakens the hydrogen bonding interaction [18]. The presence of CEA increases the content of side hydroxyl groups along with the backbone forming attract bound water. When the chemical crosslinked gel exposed to irradiation, the formation of $\mathrm{OH}$ radicals and $\mathrm{H}$ atoms a result of the radiolysis of water has occurred. The free hydroxyl group attack by the $\mathrm{OH}$ radicals leads to the formation of junction zones inside the gel network [27].

\section{Scanning electron microscope analysis}

Figure (3) shows SEM micrographs at an increasing magnification of Glut-(PVA/CEA)FULL-C60 of the PVA two molecular weights, FULL-C60 content; $0.1 \%$, irradiated at absorbed doses of $150 \mathrm{kGy}$. It can be clearly observed that the porous surface of the matrix contains the FullC60 filler inside its structure which was likely formed as agglomerates of Full-C60. The Full-C60 dispersion in (PVA-CEA) matrix was random. The pores on the surface of the polymer matrix were distributed randomly, the diameters of the pores were affected with the PVA molecular weights. It is evident that interrelated networks have been formed in the final Glut-(PVA/CEA)-Full-C60.
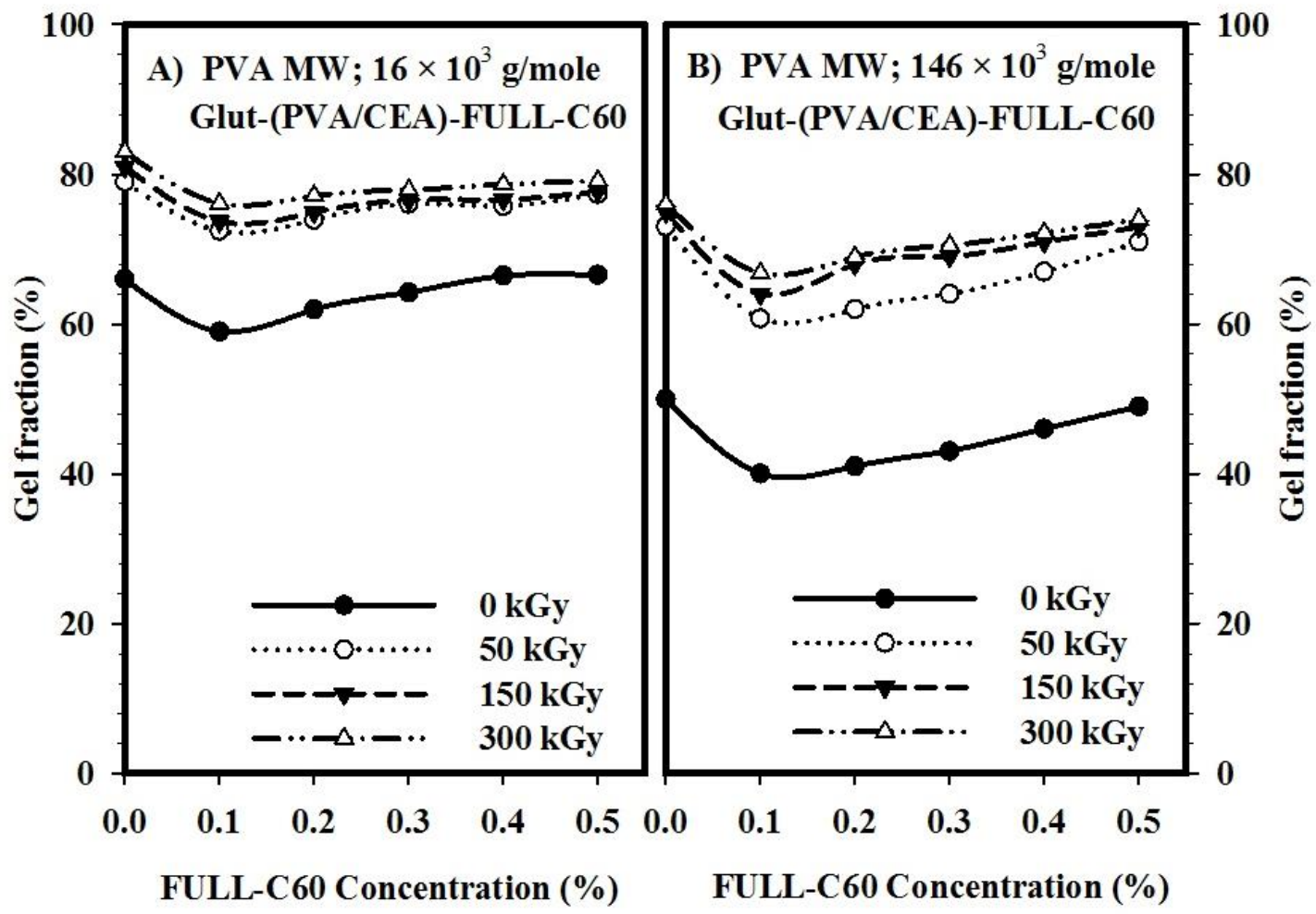

Figure (1): Gel fraction (\%) of glutaraldehyde crosslinked of A) PVA molecular weights $16 \times 10^{3}$ g/mole Glut-(PVA/CEA)FULL-C60, (B) PVA molecular weights $146 \times 10^{3}$ g/mole Glut-(PVA/CEA)-FULL-C60, as a function of irradiation dose and FULL-C60 content 


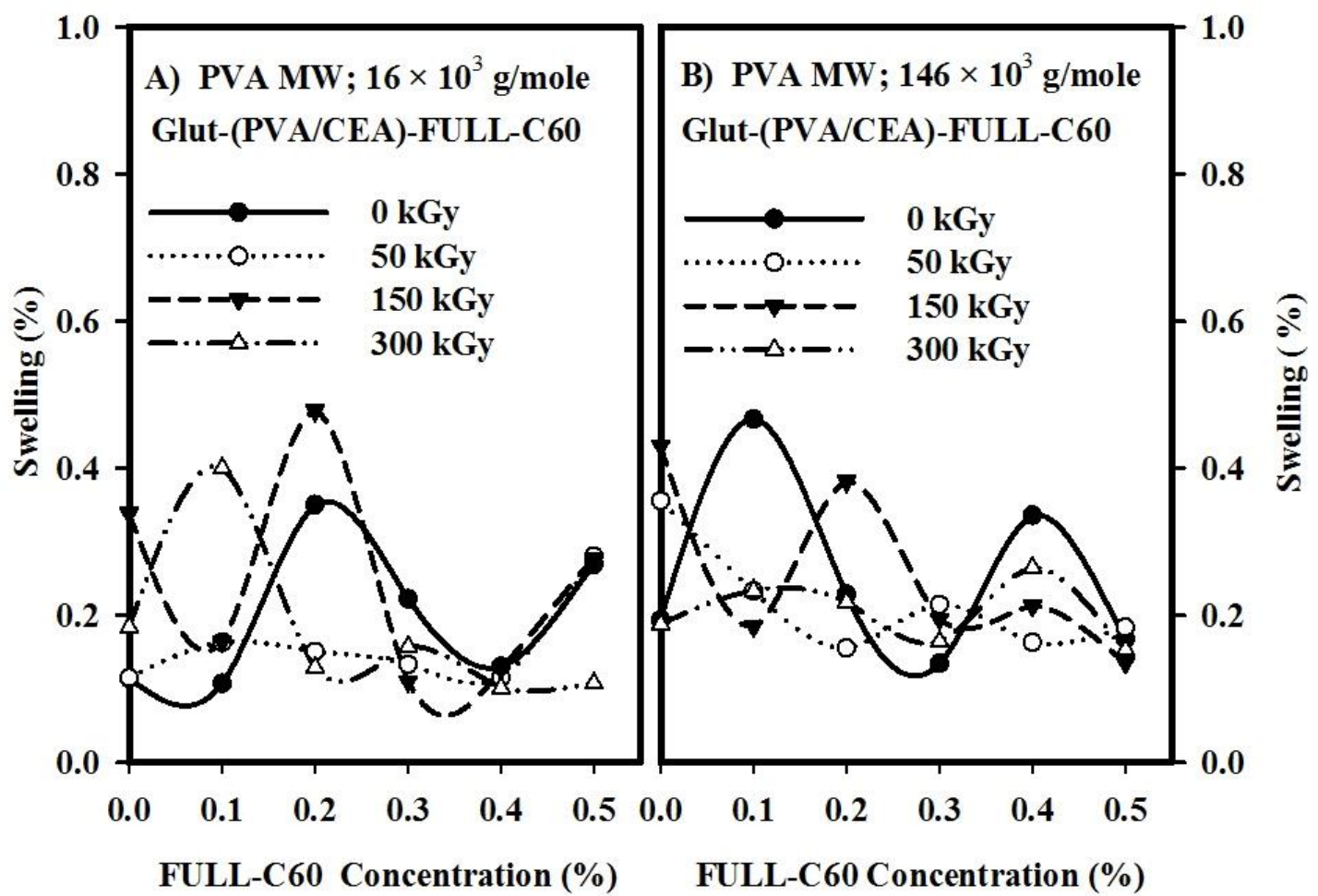

Figure (2): Degree of swelling of glutaraldehyde crosslinked of A) PVA molecular weights $16 \times 10^{3} \mathrm{~g} / \mathrm{mole}$ Glut(PVA/CEA)-FULL-C60, (B) PVA molecular weights $146 \times 10^{3} \mathrm{~g} / \mathrm{mole}$ Glut-(PVA/CEA)-FULL-C60, as a function of irradiation dose and FULL-C60 content

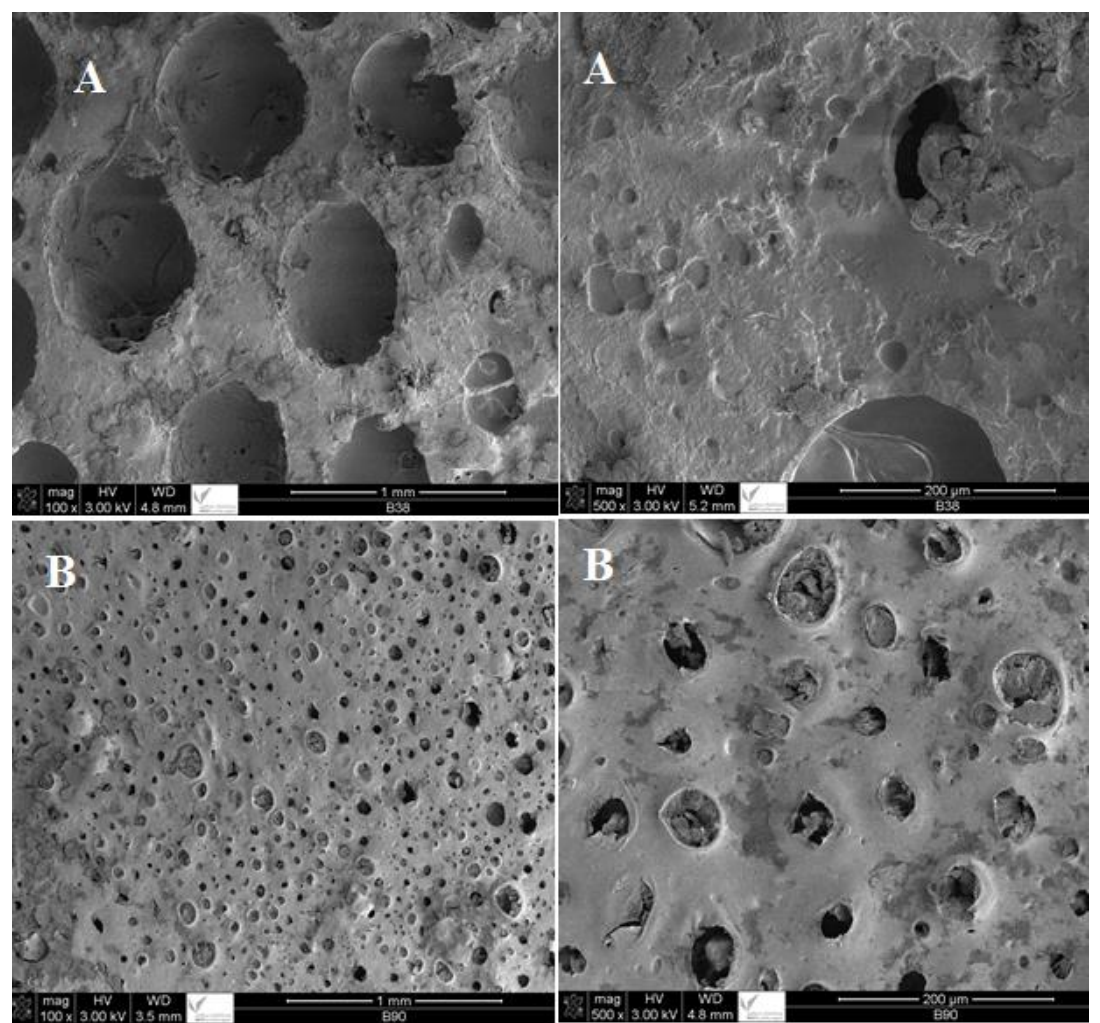

Figure (3): SEM micrographs of glutaraldehyde crosslinked of A) PVA molecular weights $16 \times 10^{3}$ g/mole Glut(PVA/CEA)-FULL-C60, (B) PVA molecular weights $146 \times 10^{3} \mathrm{~g} / \mathrm{mole}$ Glut-(PVA/CEA)-FULL-C60, FULL-C60 concentration $0.1 \%$, irradiated to absorbed doses of $150 \mathrm{kGy}$ 
Thermogravimetric analysis (TGA)

Figure (4) shows the TGA thermograms of the Glut-(PVA/CEA)-FULL-C60 of the PVA two molecular weights, Fig. 4(A, B) presents the thermograms of Full-C60 content $0-0.5 \%$ at an irradiation dose of $150 \mathrm{kGy}$. Fig. 4(C, D) shows the thermograms of Full-C60 content $0.5 \%$, at different irradiation doses up to $300 \mathrm{kGy}$. The Glut-(PVA/CEA)-Full-C60 at PVA molecular weights $16 \times 10^{3} \mathrm{~g} / \mathrm{mole}$, shows the three weightloss stages in the temperature ranges from 31 to 39 ${ }^{\circ} \mathrm{C}, 201-272{ }^{\circ} \mathrm{C}$ and $449-463{ }^{\circ} \mathrm{C}$ as presented in Table (1) as a function of the absorbed doses up to $300 \mathrm{kGy}$. The absorbed irradiation dose affects the variation of the mass loss. The first weight-loss stage is $0.52-5$ weight percent due to the evaporation of the solvent. In the second degradation stage, the mass loss was in the range from 12 to 29 weight percent which results from the degradation of Glut-(PVA/CEA)-FULL-C60 copolymer. The third stage, in the temperature range from 449 to $463{ }^{\circ} \mathrm{C}$, is due to polymer decomposition with mass loss range of 8-13 weight percent. The residual mass percent at 600 ${ }^{\circ} \mathrm{C}$ was found to be in the range of 34-18 weight percent depending on the irradiation dose. The Glut-(PVA/CEA)-FULL-C60 at PVA high molecular weights $146 \times 10^{3} \mathrm{~g} / \mathrm{mole}$ and Full-C60 concentration $0.5 \%$, exhibits three weight-loss stages in the temperature ranges from 106 to 154 ${ }^{\circ} \mathrm{C}, 230-261{ }^{\circ} \mathrm{C}$ and 477 to $491{ }^{\circ} \mathrm{C}$ as presented in Tables $(1 \& 2)$. The weight-loss stages were $0.1-1$, 38-60 and 15-24 weight percentages, relative to the irradiation dose up to $300 \mathrm{kGy}$. The residual mass percentage at $600^{\circ} \mathrm{C}$ was found to decrease in the range from 19 to 11 weight percentage with increases of the irradiation dose.

The Glut-(PVA/CEA)-FULL-C60 at PVA molecular weight $146 \times 10^{3} \mathrm{~g} / \mathrm{mole}$ at irradiated at $150 \mathrm{kGy}$, exhibits three weight-loss stages in the temperature ranges from 9 to 170,250 to $287^{\circ} \mathrm{C}$ and 480 to $493{ }^{\circ} \mathrm{C}$ as shown in Table (1). The weight-loss stages were $0.1-3,34-53$ and 5-15 of the weight percentage, as a function of the FULLC60 concentration 0- $0.5 \%$. The residual mass percentage at $600^{\circ} \mathrm{C}$ was found to decrease in the range from 7 to 12 of the weight percentage as the irradiation dose increases. This result is in accordance with the gelation results.

Dynamic Mechanical Analysis (DMA)
Dynamic mechanical analyses of the composites were directed to study the effect of FULL-C60 inclusion on the storage modulus, loss modulus, and tan delta of the prepared nanocomposite of the two PVA molecular weights.

\section{Tan delta parameters}

Figure 5(A, B) presents the Tan $\delta$ values of the blank of Glut-(PVA-CEA) and the Glut(PVA/CEA)-FULL-C60 at PVA molecular weight $16 \times 10^{3} \mathrm{~g} / \mathrm{mole}$. However, Figure $5(\mathrm{C}, \mathrm{D})$ presents Tan $\delta$ values at PVA high molecular weight $146 \times 10^{3} \mathrm{~g} / \mathrm{mole}$. The Tan $\delta$ values were measured as a function of the absorbed doses up to $300 \mathrm{kGy}$ at FULL-C60 concentration of $0.5 \%$. The Tan $\delta$ values of the blank Glut-(PVA/CEA) at PVA low molecular weight cover the temperature ranges from $20,95,19$, and $14{ }^{\circ} \mathrm{C}$. The Tan $\delta$ values of the blank Glut-(PVA/CEA) at PVA high molecular weight cover the temperature ranges from $-2,36,35$, and $31^{\circ} \mathrm{C}$ as presented in Table( 2). The thermal stability of the irradiated composite due to the crosslinking affects the variation in Tan $\delta$ values. The Tan $\delta$ values of the Glut-(PVA/CEA)-FULL-C60 at low molecular weight cover the temperature ranges of 111,44 , 45 , and $82{ }^{\circ} \mathrm{C}$. The Tan $\delta$ values of the Glut(PVA/CEA)-FULL-C60 at PVA high molecular weight cover the temperature ranges of 16,103 , $155^{\circ} \mathrm{C}$ and $105^{\circ} \mathrm{C}$ as presented in Table( 2). It is clear that the variation of the Tan $\delta$ values was affected by the irradiation doses and the addition of FULL-C60 to the (PVA/CEA) network, compared. In addition, the effect of PVA molecular weight, shift the Tan $\delta$ due to interactions between polymer chains and FULLC60[28]

\section{Storage modulus and rubbery modulus parameters} Figure $6(\mathrm{~A}, \mathrm{C})$ presents the storage modulus $\left(E^{\prime}\right)$ of the blank Glut-(PVA-CEA) at PVA molecular weight $16 \times 10^{3} \mathrm{~g} / \mathrm{mole}$ and PVA molecular weights $146 \times 10^{3} \mathrm{~g} / \mathrm{mole}$ as a function of the absorbed doses up to $300 \mathrm{kGy}$, the plots of $E$, versus temperature. The $E$ ' for the blank Glut(PVA-CEA) composites at $0 \mathrm{kGy}$ are higher than most of the irradiated Glut-(PVA-CEA) composites for both PVA molecular weights and the storage modulus decreased significantly upon increasing the absorbed dose. This result may be due to the degradation process of gamma irradiation as the crosslinking agent. The curves 
show three distinct regions, the glassy state, glass to rubber transition region, and the rubbery state.
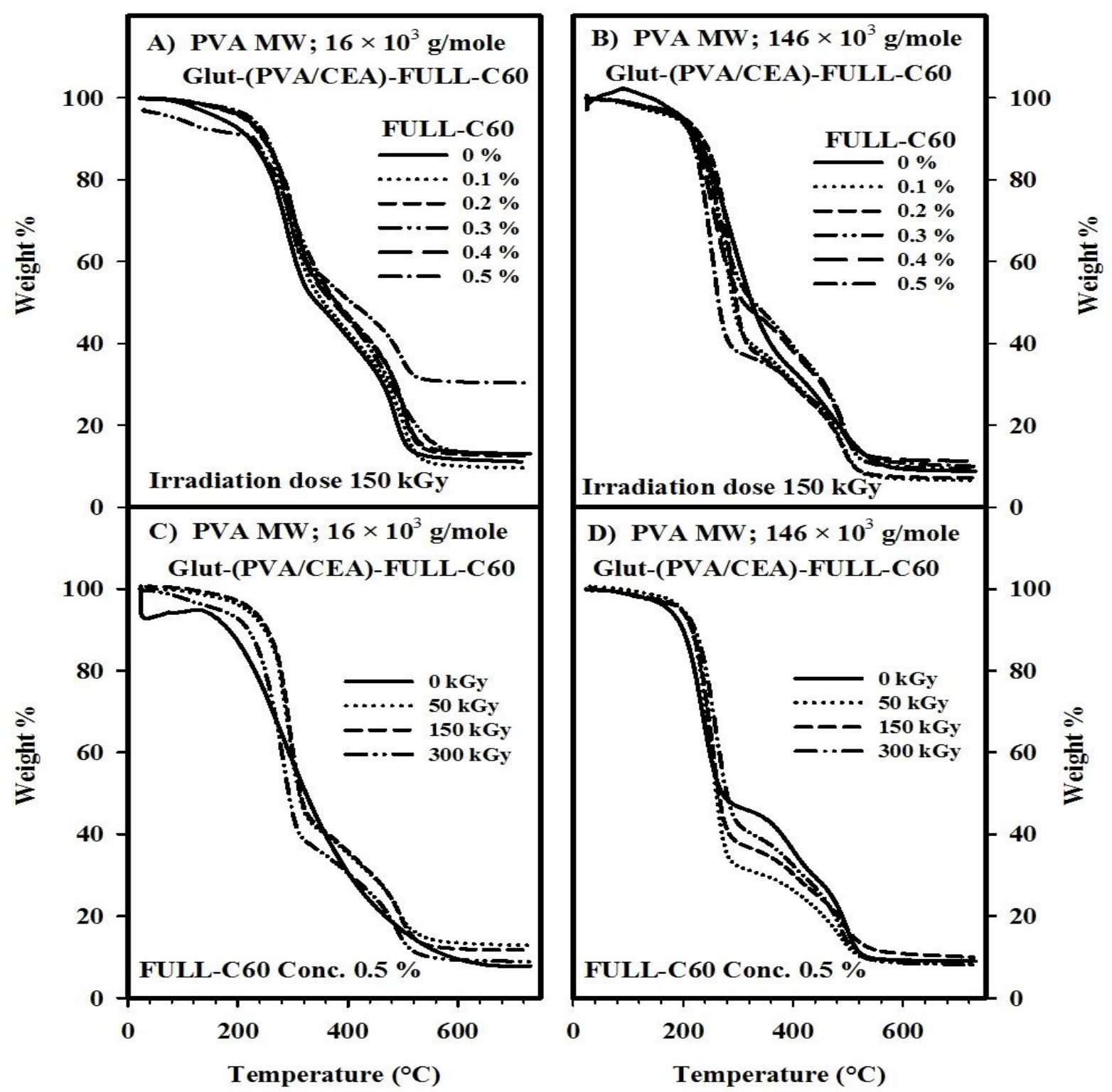

Figure (4): TGA thermograms of glutaraldehyde crosslinked of A) PVA molecular weights $16 \times 10^{3}$ g/mole Glut(PVA/CEA)-FULL-C60, (B) PVA molecular weights $146 \times 10^{3} \mathrm{~g} / \mathrm{mole}$ Glut-(PVA/CEA)-Full-C60, Full-C60 concentration $0.5 \%$, irradiated at absorbed doses up to $300 \mathrm{kGy}$ 
Table( 1): DTG data $T_{\text {Onset }}$ and $T_{\text {Peak }}$ of Glut-(PVA/CEA)-Full-C60 of A) PVA MW $16 \times 10^{3}$ g/mole, (B) PVA MW $146 \times 10^{3}$ g/mole. Full-C60 concentration $0.5 \%$, irradiated up to $300 \mathrm{kGy}$

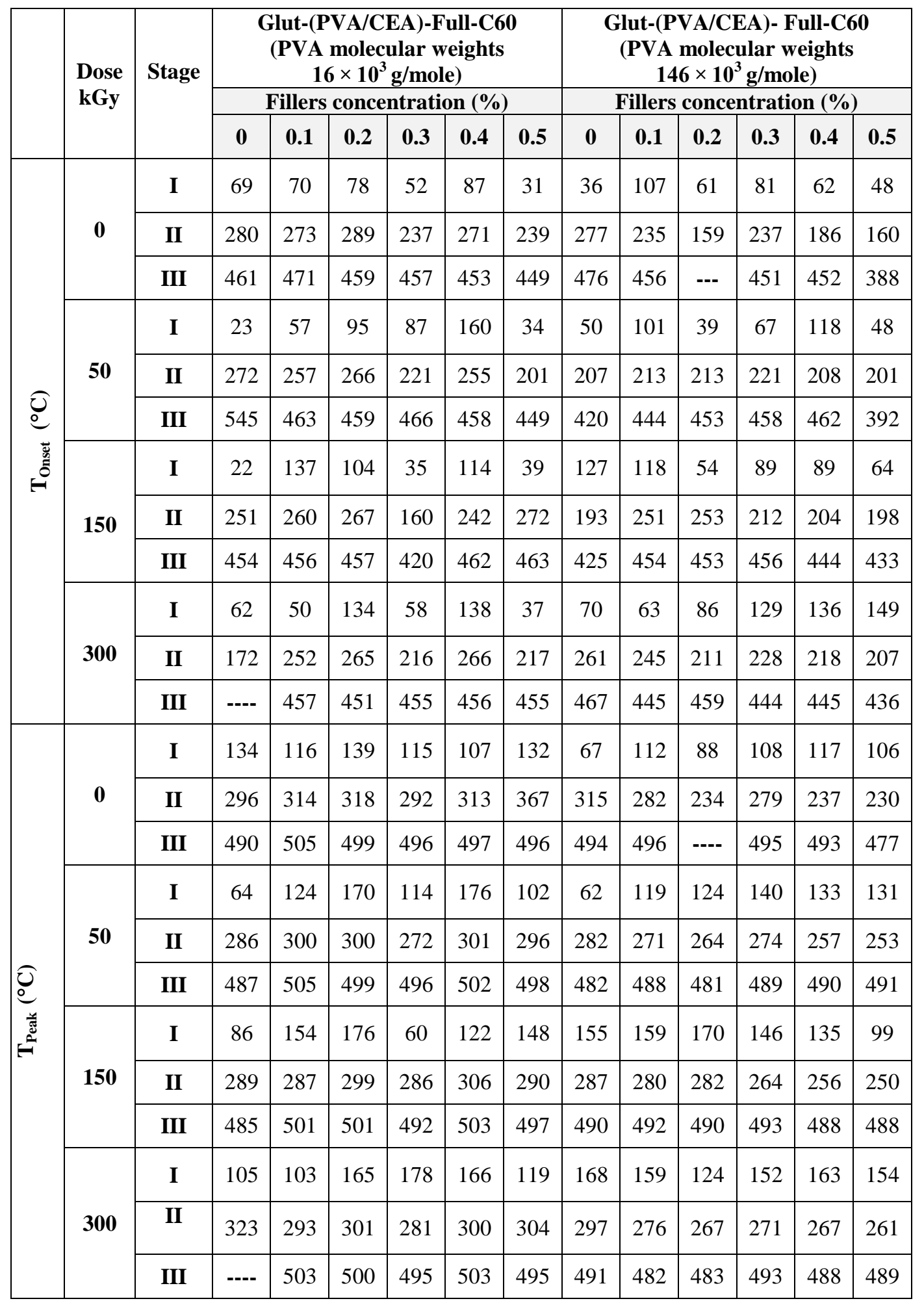




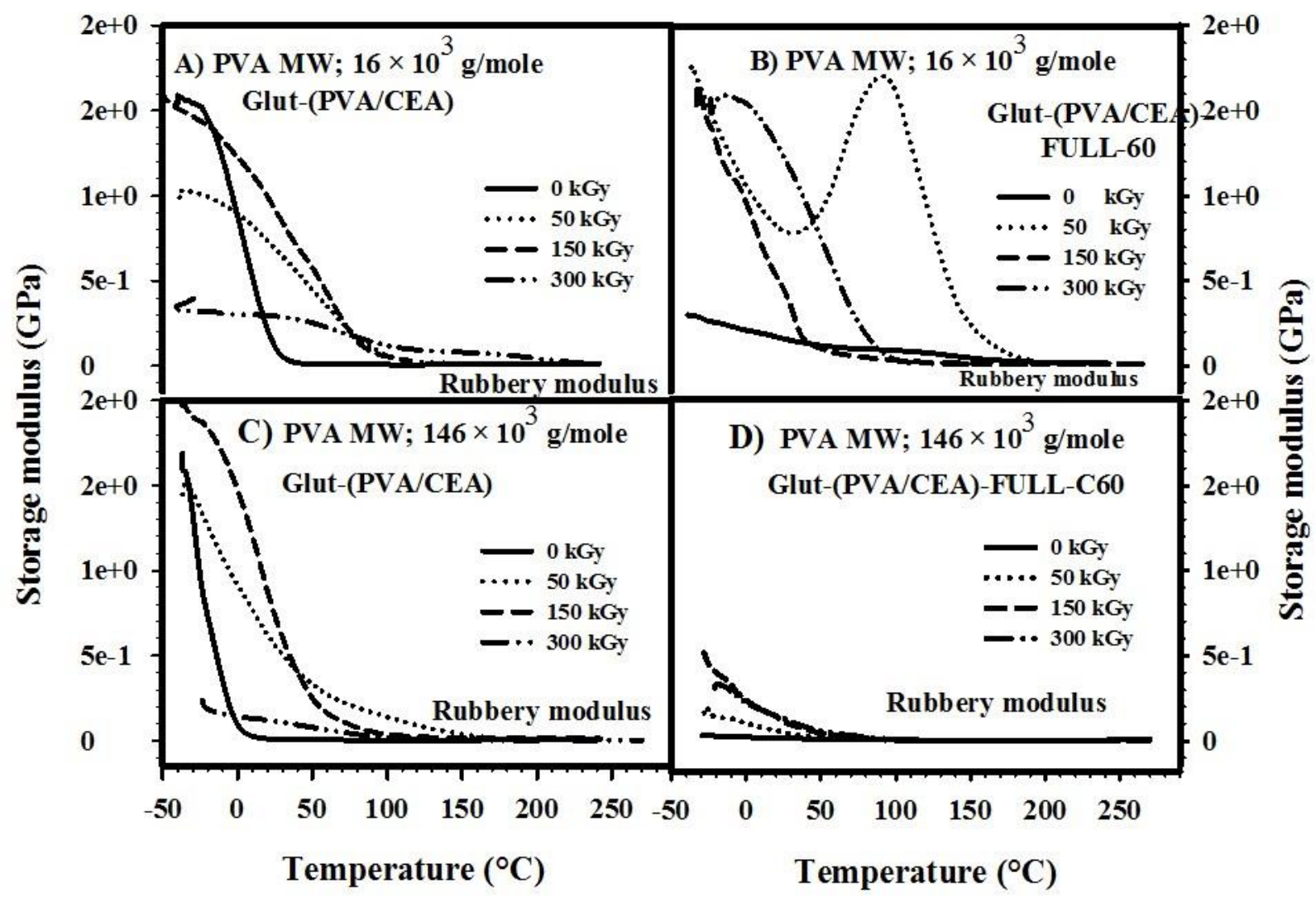

Figure (6): Storage and rubbery moduli of FULL-60 concentration $0.5 \%$ as a function of absorbed dose up to $300 \mathrm{kGy}$. (A): Blank Glut-(PVA-CEA) of PVA molecular weights $16 \times 10^{3} \mathrm{~g} / \mathrm{mole}$ (B): Glut-(PVA/CEA)-FULL-C60 of PVA molecular weights $16 \times 10^{3} \mathrm{~g} / \mathrm{mole}(\mathrm{C})$ : Blank Glut-(PVA-CEA) of PVA molecular weights $146 \times 10^{3} \mathrm{~g} / \mathrm{mole}$ and (D): Glut(PVA/CEA)-FULL-C60 of PVA molecular weights $146 \times 10^{3} \mathrm{~g} / \mathrm{mole}$

The storage modulus of the Glut-(PVA/CEA)FULL-C60 at both molecular weight FULL-C60 concentration $0.5 \%$ as a function of the absorbed doses up to $300 \mathrm{kGy}$. As shown in Figure 6(B, D) the E' for the Glut-(PVA-CEA)-FULL-C60 composites of PVA low molecular weight are significantly higher than that of PVA high molecular weight Glut-(PVA-CEA)-FULL-C60 composites and the storage modulus increased significantly with increasing the absorbed dose. This result may be due to the crosslinking process of gamma irradiation as a crosslinking agent.

The rubbery modulus (Er) appears as a plateau in Fig. 6(A, B, C, D). The Er values in mega Pascal (MPa) at $200{ }^{\circ} \mathrm{C}$ of the Glut-(PVA/CEA) at PVA low molecular weight cover the ranges of 1.1, 15, 39 , and $12 \mathrm{MPa}$ of absorbed doses up to $300 \mathrm{kGy}$. The Er values at $200{ }^{\circ} \mathrm{C}$ of the Glut-(PVA/CEA) at PVA high molecular weight cover the ranges of 1.4, 2.6, 4.4, and 0.7 MPa of the same absorbed dose. However, in the case of the Glut-
(PVA/CEA)-FULL-C60 at the PVA low molecular weight the Er values span, the ranges of 22, 19, 16, and 9.1 MPa. The Er values at the PVA high molecular weight span in the ranges of 2, 0.7, 0.7, and $0.5 \mathrm{MPa}$ as presented in Table (2). The variation in rubbery modulus is significant and could be attributed to the addition of the CEA. The presence of FULL-C60 acts as fillers, and finally the absorbed dose in kGy. According to these results, the elevated rubbery modulus could be ascribed to the higher crosslink-density in the Glut-(PVA/CEA) and Glut-(PVA/CEA)-FULL$\mathrm{C} 60$, in addition to the effect of the irradiation dose and the PVA molecular weights.

\section{Loss modulus parameters}

Figure $7(\mathrm{~A}, \mathrm{C})$ presents the loss modulus $\left(\mathrm{E}^{\prime \prime}\right)$ of the blank Glut-(PVA-CEA) at PVA molecular weight $16 \times 10^{3} \mathrm{~g} / \mathrm{mole}$, PVA molecular weight $146 \times 10^{3} \mathrm{~g} / \mathrm{mole}$ and Fig.7(B, D) presents the E" of the Glut-(PVA/CEA)-FULL-C60 at both PVA molecular weights irradiated at $150 \mathrm{kGy}$, as a 
function of the FULL-C60 concentration $0-0.5$ percentage. The PVA composites show a peak transition temperature. The irradiated Glut-(PVACEA) exhibited a greater E" than the unirradiated one in both of the PVA molecular weights. This may be due to the crosslinking effect of gamma irradiation.

It is clear that the variance of the loss modulus values is affected by the addition of FULL-C60 to maximum corresponding approximately to the glass

the (PVA/CEA) network in different concentrations. Also the effect of PVA molecular weights shifts the loss modulus due to interactions between polymer chains and FULL-C60. The filler concentration and PVA molecular weights were effective in the loss modulus values

Table (2):Tan Delta and rubbery modulus of FULL-C60 at concentration of $0.5 \%$ using two molecular weights of PVA as a function of absorbed dose up to $300 \mathrm{kGy}$ for blank Glut-(PVA/CEA) and Glut-(PVA/CEA)-FULL-C60

\begin{tabular}{|c|c|c|c|c|c|}
\hline & Samples detail & $\begin{array}{c}\text { FULL-C60 } \\
\text { Conc. }\end{array}$ & $\begin{array}{l}\text { Dose } \\
\text { kGy }\end{array}$ & $\begin{array}{c}\text { Tan } \delta \\
{ }^{\circ} \mathbf{C}\end{array}$ & $\begin{array}{l}\text { Rubbery modulus } \\
(\mathrm{MPa}) \text { at } 150{ }^{\circ} \mathrm{C}\end{array}$ \\
\hline \multirow{8}{*}{ 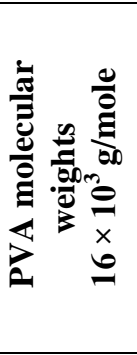 } & \multirow{4}{*}{ Glut-(PVA/CEA) } & 0.0 & 0 & 20 & 1.1 \\
\hline & & 0.0 & 50 & 95 & 15 \\
\hline & & 0.0 & 150 & 19 & 38 \\
\hline & & 0.0 & 300 & 14 & 12 \\
\hline & \multirow{4}{*}{$\begin{array}{c}\text { Glut-(PVA/CEA)- } \\
\text { FULL-C60 }\end{array}$} & 0.5 & 0 & 111 & 21 \\
\hline & & 0.5 & 50 & 44 & 19 \\
\hline & & 0.5 & 150 & 45 & 15 \\
\hline & & 0.5 & 300 & 82 & 9.1 \\
\hline \multirow{8}{*}{ 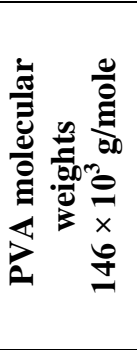 } & \multirow{4}{*}{ Glut-(PVA/CEA) } & 0.0 & 0 & -2 & 1.4 \\
\hline & & 0.0 & 50 & 36 & 2.6 \\
\hline & & 0.0 & 150 & 35 & 4.4 \\
\hline & & 0.0 & 300 & 31 & 0.7 \\
\hline & \multirow{4}{*}{$\begin{array}{c}\text { Glut-(PVA/CEA)- } \\
\text { FULL-C60 }\end{array}$} & 0.5 & 0 & 16 & 2 \\
\hline & & 0.5 & 50 & 103 & 0.7 \\
\hline & & 0.5 & 150 & 155 & 0.7 \\
\hline & & 0.5 & 300 & 105 & 0.5 \\
\hline
\end{tabular}

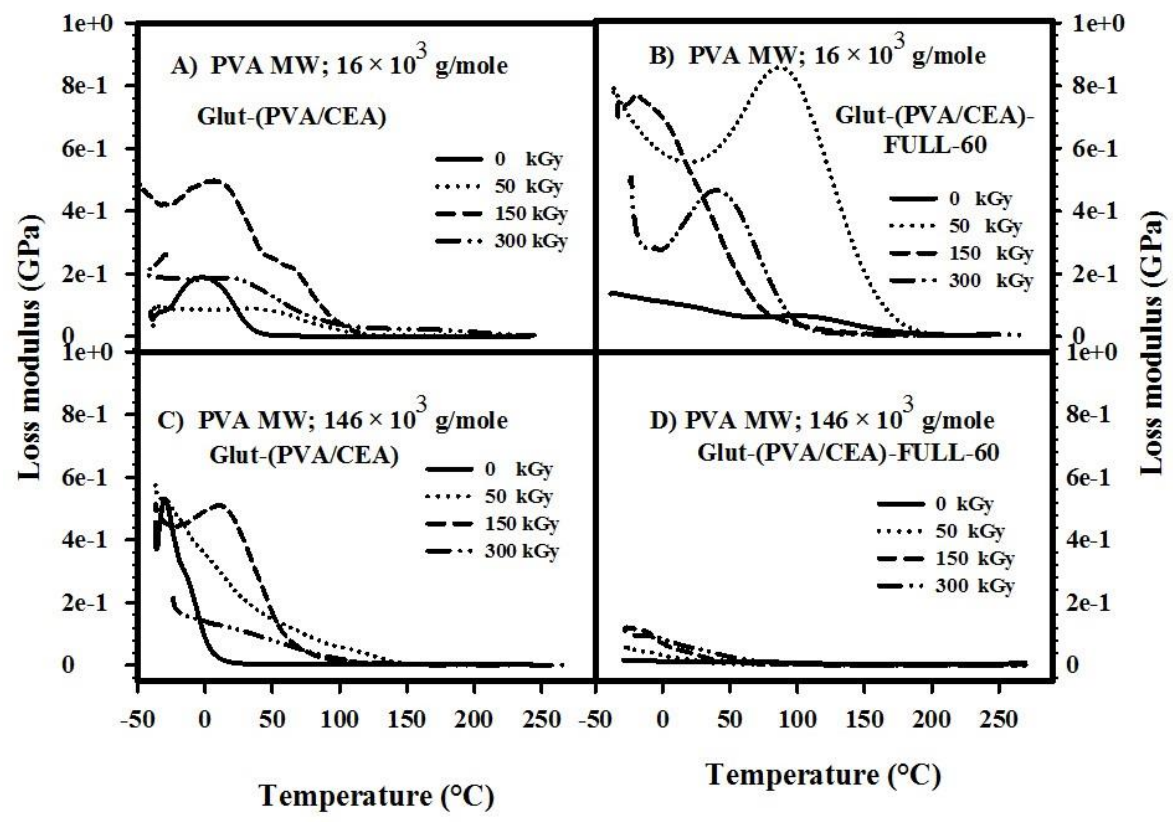

Figure (7): Loss modulus of FULL-60 concentration $0.5 \%$ as a function of absorbed dose up to $300 \mathrm{kGy}$. (A): Blank Glut(PVA-CEA) of PVA molecular weights $16 \times 10^{3} \mathrm{~g} / \mathrm{mole}$, (B): Glut-(PVA/CEA)-FULL-C60 of PVA molecular weights 
$16 \times 10^{3} \mathrm{~g} / \mathrm{mole},(\mathrm{C})$ : Blank Glut-(PVA-CEA) of PVA molecular weights $146 \times 10^{3} \mathrm{~g} / \mathrm{mole}^{2}$ and (D): Glut-(PVA/CEA)-FULLC60 of PVA molecular weights $146 \times 10^{3} \mathrm{~g} / \mathrm{mole}$

\section{Conclusions}

The preparation and characterization of chemical crosslinked poly (vinyl alcohol) of molecular weights $16 \times 10^{3} \mathrm{~g} / \mathrm{mole}$ and $146 \times 10^{3} \mathrm{~g} / \mathrm{mole}$ in the presence of 2-carboxyethyl acrylate oligomers and fullerene (FULL-C60) fillers followed by gamma irradiation were conducted. The swelling and gelation behavior of the prepared nanocomposite were studied. A significant reduction in swelling and an increase in gelation of both unirradiated and irradiated glutaraldehyde crosslinked nanocomposites were observed. The scanning electron microscopy micrographs of the Glut-(PVA-CEA)-FULL-C60 nanocomposites were investigated showing a homogeneous distribution of composite matrix. The results of TGA analyses indicated that the FULL-C60 addition and the exposure to gamma radiation improve the thermal stabilities of chemical crosslinking polymeric nanocomposites. The dynamic mechanical analysis with the Tan Delta with temperature values around $\mathrm{T}_{\mathrm{g}}$. The storage modulus ( $\left.\mathrm{E}^{\prime}\right)$, loss modulus ( $\left.\mathrm{E}^{\prime \prime}\right)$, and $\mathrm{Er}$ were determined for the irradiated Glut-(PVA-CEA) and Glut-(PVA-CEA)-Fillers. The fullerene C60 and the gamma irradiation improve the thermal and mechanical properties of the chemical crosslinking PVA nanocomposites.

\section{Declaration of Competing Interest}

The authors declare that they have no known competing financial interests or personal relationships that could have appeared to influence the work reported in this study.

\section{Acknowledgment}

The research team expresses great appreciation to KACST (KACST ASTP-09) for funding this project.

\section{References}

1. Kroto H. The Birth of C60: Buckminsterfullerene 1993;117:1-7. https://doi.org/10.1007/978-3-642-85049-3_1.

2. Zuev V V. Polymer nanocomposites containing fullerene C60 nanofillers. Macromol Symp 2011;301:157-61. https://doi.org/10.1002/masy.201150320.

3. Cadek M, Coleman JN, Barron V, Hedicke K,
Blau WJ. Morphological and mechanical properties of carbon-nanotube-reinforced semicrystalline and amorphous polymer composites. Appl Phys Lett 2002;81:5123-5. https://doi.org/10.1063/1.1533118.

4. Sumlo Iijima. Helical microtubules of graphitic carbon. Nature 1991;354:56-8.

5. [Iijima S. Direct Observation of the Tetrahedral Bonding in Graphitized Carbon Black By. J Cryst Growth 1980;50:675-83.

6. [6] Anufrieva EV, Krakovyak MG, Anan'eva TD, Nekrasova TN, Smyslov RY. Interaction of polymers with fullerene C60. Phys Solid State 2002;44:461-2. https://doi.org/10.1134/1.1462672.

7. Hurtgen M, Debuigne A, Mouithys-Mickalad A, Jérôme R, Jérôme C, Detrembleur C. Synthesis of poly(vinyl alcohol)/C60 and poly(N- vinylpyrrolidone)/C60 nanohybrids as potential photodynamic cancer therapy agents. Chem - An Asian J 2010;5:859-68. https://doi.org/10.1002/asia.200900277.

8. Wen X, Min J, Tan H, Gao D, Chen X, Szymańska K, et al. Reactive construction of catalytic carbonization system in $\mathrm{PP} / \mathrm{C} 60 / \mathrm{Ni}(\mathrm{OH}) 2$ nanocomposites for simultaneously improving thermal stability, flame retardancy and mechanical properties. Compos Part A Appl Sci Manuf 2020;129. https://doi.org/10.1016/j.compositesa.2019.105 722.

9. Fang H, Bai SL, Wong CP. Microstructure engineering of graphene towards highly thermal conductive composites. Compos Part A Appl Sci Manuf 2018;112:216-38. https://doi.org/10.1016/j.compositesa.2018.06. 010 .

10. Gandhi M V., Thompson BS, Kasiviswanathan SR, Choi SB. A collage of experimental investigations on smart fibrous composite structures and mechanical systems featuring electro-rheological fluids, piezoelectric materials and fiber-optic sensors. Compos Eng $1992 . \quad$ https://doi.org/10.1016/09619526(92)90043-6.

11. Cheng X, Putz KW, Wood CD, Brinson LC. Characterization of local elastic modulus in confined polymer films via AFM indentation. Macromol Rapid Commun 2015;36:391-7. https://doi.org/10.1002/marc.201400487.

12. Raafat AI, Abd-Allah WM. In vitro apatite forming ability and ketoprofen release of radiation synthesized (gelatin-polyvinyl alcohol)/bioglass composite scaffolds for bone tissue regeneration. Polym Compos 2018;39:606-15. 
https://doi.org/10.1002/pc.23974.

13. Saif MJ, Naveed M, Asif HM, Akhtar R. Irradiation applications for polymer nanocomposites: A state-of-the-art review. J Ind Eng Chem 2018;60:218-36. https://doi.org/10.1016/j.jiec.2017.11.009.

14. Szafulera K, Wach RA, Olejnik AK, Rosiak JM, Ulański P. Radiation synthesis of biocompatible hydrogels of dextran methacrylate. Radiat Phys Chem 2018;142:115-20. https://doi.org/10.1016/j.radphyschem.2017.01 .004 .

15. A. Abaza, E. A. Hegazy, Ghada. A. Mahmoud, B. Elsheikh. Characterization and Antitumor Activity of Chitosan/Poly (Vinyl Alcohol) Blend Doped with Gold and Silver Nanoparticles in Treatment of Prostatic Cancer Model. J Pharm Pharmacol 2018;6:659-73. https://doi.org/10.17265/23282150/2018.07.003.

16. Hegazy E-SA, Abd El-Rehim HA, Khalifa NA, Atwa SM, Shawky HA. Anionic/Cationic Membranes Obtained by a Radiation Grafting Method for Use in Waste Water Treatment. Polym Int 1997;43:321-32. https://doi.org/10.1002/(sici)10970126(199708)43:4<321::aid-pi756>3.0.co;2-j.

17. Ali AEH, Raafat AI, Mahmoud GA, Badway NA, El-Mottaleb MA, Elshahawy MF. Photocatalytic Decolorization of Dye Effluent Using Radiation Developed Polymeric Nanocomposites. J Inorg Organomet Polym Mater 2016;26:606-15. https://doi.org/10.1007/s10904-016-0346-2.

18. Du H, Zhang J. Shape memory polymer based on chemically cross-linked poly(vinyl alcohol) containing a small number of water molecules. Colloid Polym Sci 2010;288:15-24. https://doi.org/10.1007/s00396-009-2117-x.

19. Dubey KA, Bhardwaj YK, Chaudhari C V, Sabharwal S. LDPE / EVA / PCR / MWNT Nanocomposites: Radiation Crosslinking and Physicomechanical Characteristics 2011. https://doi.org/10.1002/pc.

20. Lotfy S, Atta A, Abdeltwab E. Comparative study of gamma and ion beam irradiation of polymeric nanocomposite on electrical conductivity. J Appl Polym Sci 2018;135:46146. https://doi.org/10.1002/app.46146.

21. Basfar AA, Lotfy S. Radiation-crosslinking of shape memory polymers based on poly(vinyl alcohol) in the presence of carbon nanotubes. Radiat Phys Chem 2015;106:376-84. https://doi.org/10.1016/j.radphyschem.2014.08 .024 .

22. Ge Q, Luo X, Rodriguez ED, Zhang X, Mather
PT, Dunn ML, et al. Thermomechanical behavior of shape memory elastomeric composites. J Mech Phys Solids 2012;60:6783. https://doi.org/10.1016/j.jmps.2011.09.011.

23. Alfayyadh AAM, Lotfy S, Basfar AA, Khalil MI. Influences of poly (vinyl alcohol) molecular weight and carbon nanotubes on radiation crosslinking shape memory polymers. Prog Nat Sci Mater Int 2017;27. https://doi.org/10.1016/j.pnsc.2017.04.015.

24. Du H, Zhang J. Solvent induced shape recovery of shape memory polymer based on chemically cross-linked poly(vinyl alcohol). Soft Matter 2010;6:3370. https://doi.org/10.1039/b922220k.

25. Hirai T, Maruyama H, Suzuki T, Hayashi S. Effect of chemical cross-linking under elongation on shape restoring of poly(vinyl alcohol) hydrogel. J Appl Polym Sci 1992;46:1449-51. https://doi.org/10.1002/app.1992.070460815.

26. Andersson MG, Jarvid M, Johansson A, Gubanski S, Foreman MRSJ, Müller C, et al. Dielectric strength of $\gamma$-radiation cross-linked, high vinyl-content polyethylene. Eur Polym J 2015;64:101-7. https://doi.org/10.1016/j.eurpolymj.2014.11.04 2.

27. Cui H, Yan X, Monasterio M, Xing F. Effects of Various Surfactants on the Dispersion of MWCNTs-OH in Aqueous Solution. Nanomaterials 2017;7:262. https://doi.org/10.3390/nano7090262.

28. Zhogova KB, Davydov IA, Punin VT, Troitskii $\mathrm{BB}$, Domvachiev GA. Investigation of fullerene C60effect on properties of polymethylmethacrylate exposed to ionizing radiation. Eur Polym J 2005;41:1260-4. https://doi.org/10.1016/j.eurpolymj.2005.01.01 0 .

Arab J. Nucl. Sci. \&Applic. Vol. 54, No. 1 (2021) 